\title{
Navigating the Ethically Complex and Controversial World of College Athletics: A Humanistic Leadership Approach to Student Athlete Well-Being
}

\author{
Jay L. Caulfield ${ }^{1}$ (D) Felissa K. Lee ${ }^{2}$ - Catharyn A. Baird ${ }^{3,4}$
}

Received: 19 November 2020 / Accepted: 17 December 2021 / Published online: 29 January 2022

(c) The Author(s), under exclusive licence to Springer Nature B.V. 2021

\begin{abstract}
The college athletics environment within the USA is ethically complex and often controversial. From an academic standpoint, athletes are often viewed as a privileged class receiving undue benefit. Yet closer inspection reveals that student athletes are at risk psychologically, physically, and intellectually in ways that undermine development and flourishing. This reality stands in troubling contrast to the prosocial, virtue-based goals expressed by university mission statements. Given the role of sport in many university business models, college athletics invites scrutiny from a business ethics standpoint. Using a humanistic leadership perspective (Pirson in: Humanistic management: protecting dignity and promoting well-being, Cambridge University Press, Cambridge, 2017), we organize our analysis around three challenges facing the college athletics system: (1) navigating the tension between claiming college athletes are amateurs rather than professionals; (2) defining the ethical edge between winning and winning fairly; and (3) moderating the insatiable drive to win while protecting student athlete well-being. We then articulate three strategies for successfully addressing these challenges: leadership role modeling, putting structural supports in place and holding people accountable. We argue that humanistic leadership and a 'balanced motivational drive mindset' (Lawrence and Nohria in: J Bus Ethics 128:383-394, 2002, https://doi.org/10.1007/s10551014-2090-2; Pirson 2017) could help move college athletics from an economistic model toward a more humanistic model that prioritizes the dignity and well-being of its participants, particularly student athletes.
\end{abstract}

Keywords College athletics $\cdot$ Moral failure and moral success $\cdot$ Humanistic leadership $\cdot$ Dignity $\cdot$ Well-being and flourishing

Jay L. Caulfield

jay.caulfield@marquette.edu

Felissa K. Lee

felissa.lee@marqette.edu

Catharyn A. Baird

cbaird@ethicsgame.com

1 College of Business Administration, Department of Management, Marquette University, Straz Hall, 219, P.O. Box 1881, Milwaukee, WI 53201-1881, USA

2 College of Business Administration, Department of Management, Marquette University, Straz Hall, 220, P.O. Box 1881, Milwaukee, WI 53201-1881, USA

3 EthicsGame, 6 Inverness Court East, Suite 220, Engelwood, CO 80112, USA

4 Regis University, Denver, CO, USA

\section{The Opportunity}

During times of great change, ethical leaders have the opportunity to help those impacted navigate the emerging reality with clarity and wisdom. The world of college athletics is currently undergoing such a sea-change. The challenge for leaders is that previously unaccepted behaviors (for example, athletes getting paid for their image) are now deemed ethical; clear guidelines have yet to be established for implementing new practices. Choosing a moral path forward will require discerning the array of behaviors that best harmonize values in tension within the community.

College athletics now faces three key challenges to its value priorities, challenges which mirror values in tension within many organizational settings. The first challenge is navigating the tension between generating revenue for the universities and athletic organizations by defining college athletes as amateurs or blurring definitional lines through 
compensating athletes and treating them more as professionals. With new rules on the horizon, governing how college athletes can monetize their name/image/likeness (NIL), the prevailing economic model is in flux. The second challenge is defining the perennial ethical edge between winning and winning fairly where power dynamics between leaders and athletes shape ethical expectations and can either support or thwart the moral development of the athlete. The third challenge is moderating an insatiable drive to win, which results in winking at the mistreatment of student athletes in the process.

The humanistic leadership perspective is a promising guide for navigating these challenges as it reflects both the desire to achieve and the desire to be ethical. Michael Pirson (2017) explains, "[a]ccording to the humanistic perspective, the key reason for the survival of humans is their relational nature, for which dignity and morality are crucial. Their highest aspiration is to achieve a level of well-being and to flourish" (p. 62). The humanistic leadership perspective stands in contrast to the prevailing economistic perspective that often drives the culture of college athletics programs and that risks compromising the well-being of student athletes.

The purpose of this paper is to examine how the humanistic leadership perspective can promote systems in which athletes are treated with respect and care for their well-being even as they are coached to win. To this end, our paper proceeds as follows. We begin by elaborating upon the principles of humanistic leadership that can help leaders focus on harmonizing the tension among the conflicting values present in college athletics (Lawrence \& Pirson, 2015; Pirson, 2017). We highlight the difference between the humanistic and economistic perspectives and describe the implications of each for the culture, decision-making, and student experience within college athletic programs. Next, we provide examples of the three challenges in light of practices embedded in the current system that detract from the safety and well-being of student athletes. These examples are not exhaustive but were rather selected to illustrate a core set of concerns that bear on the moral subculture within college athletics. Then, operating from the lens of humanistic leadership (Lawrence \& Pirson, 2015), we suggest strategies for successfully re-aligning intercollegiate athletics with the values of higher education in order to keep the promises that higher education makes to all students. We conclude with our discussion and identify directions for future research.

This work contributes to the literature in three ways. First, although elements of the student athlete experience have been studied in the sport management literature (Cole \& Martin, 2018; Fransen et al., 2020; Gearity \& Murray, 2011; Lopez et al., 2020), we are unaware of any publications in the mainstream business ethics literature that examine the intercollegiate athletics system as a setting for the dynamics of organizational ethics from the lens of humanistic leadership to ensure the goals of athletic programs align with the mission of colleges and universities (Cortés-Sanchez, 2018).

A second contribution is to bring humanistic leadership to bear on the issue of motivation strategies in high-performance environments such as competitive sport. In highly competitive industries like intercollegiate athletics, high tech services and investment banking, leaders mistakenly assume fear is the most effective way to get the best out of people (Elison \& Partridge, 2012; Yukhymenko-Lescroat et al., 2015). However, a more supportive humanistic leadership approach, which respects the dignity of participants, has strong motivating potential (Jenny \& Hushman, 2014). Adopting a humanistic leadership lens does not mean lowering standards; instead, participants in the athletic enterprise can strive for excellence in ways that respect the dignity of all and draw on a broad range of needs underlying human motivation, thereby achieving a higher level of well-being than what currently exists (Lawrence \& Pirson, 2015; Lawrence \& Nohria, 2002; McDonald, 2012; Nohria et al., 2008; Waddock, 2016).

Third, this article fills a gap in the literature as little academic work explores how adopting humanistic leadership throughout the intercollegiate sports system might consistently create environments that provide student athletes better opportunities to flourish and how this approach to leadership supports the mission of universities and higher education as a whole. Next, we begin by defining moral community, moral failure and humanistic leadership.

\section{Moral Community, Moral Failure and Humanistic Leadership}

Broadly stated, a social system is comprised of a group of actors and entities who share a common interest that connects them through social interactions, structure and influence. Every social system is comprised of various moral communities, each with a set of behavioral expectations informed by the values and ideals of dominant actors within the system. Moral communities are associated with a set of formal and informal rules. Moral failure occurs when stakeholders fail to comply with these social expectations or engage in behaviors that they or others consider unethical (Shadnam \& Lawrence, 2011, p. 700). The system's internal and external drivers of change are equally important when a moral community constructs, or reevaluates, the governing set of moral rules (Shadnam \& Lawrence, 2011). The greater the divide between the ethical expectations of various members of the community and the community at large, the more likely change will occur within that social system (Shadnam \& Lawrence, 2011). In our analysis we address the moral community of college athletics, and how 
humanistic leadership can help to shift the norms and behaviors of this community further toward supporting the wellbeing of student athletes.

The two pillars of humanistic leadership are dignity and shared well-being (Lawrence \& Pirson, 2015; Pirson, 2017). Further, the humanistic leadership perspective builds upon four drive motivation theory (Lawrence \& Nohria, 2002; Lawrence \& Pirson, 2015; Pirson, 2017). Based upon evidence from the fields of evolutionary biology, anthropology, neuroscience and neuropsychology, these four motivational drives include: the drive to acquire; the drive to defend; the drive to bond; and the drive to learn (Lawrence \& Nohria, 2002; Nohria et al., 2008). A key principle underlying humanistic leadership is the importance of the balanced drive mindset: that each of these drives is important and influential in its own right in motivating human behavior and that no subset of the drives should be overemphasized indefinitely. By contrast, the economistic perspective places heavy emphasis on profit and winning, thereby drawing out the motivational drives to acquire and to defend. Over time this lack of balance risks undermining the well-being and ethical health of individuals and communities (Lawrence \& Pirson, 2015; Pirson, 2017). As later sections of the article will illustrate, each motivational drive has moral implications for leadership (Lawrence \& Nohria, 2002; Lawrence \& Pirson, 2015).

In the case of intercollegiate athletics, practicing humanistic leadership - upholding the dignity of all participants and seeking the shared well-being of all-is supported by accrediting bodies who expect the dominant actors within higher education to organize people and processes around the ideals currently present within most university mission statements (Cortés-Sanchez, 2018). This goal is difficult to achieve under the best of conditions but impossible to achieve within an unbalanced social system focusing on the drive to acquire and the drive to defend while subordinating the drive to bond and the drive to learn. To fully live into dignity and well-being, humanistic leadership requires motivational drive balance.

Viewing collegiate athletics through a humanistic leadership lens, we argue that moral failure happens when human dignity is breached, rights are violated, or development is hindered in the unrelenting quest for acquiring resources and adulation and defending one's status within the larger community. From the humanistic leadership perspective "any...constraint upon freedom and deprivation of power which either insults or humiliates is normatively unacceptable" (Morriss as cited in Haugaard \& Clegg, 2009, p. 6). Implicit in this expectation is the notion that a community needs to ensure that the existing power structures support tolerance and self-agency, which flow from having dignity and respect for every human being with the ultimate goal of shared well-being (Bazerman \& Tenbrunsel, 2011).
In the balance of this paper we analyze three key challenges facing intercollegiate athletics today using a humanistic leadership lens and balanced drive mindset. We turn next to an overview of the context in which these challenges emerge on university campuses.

\section{Intertwined and Complex Challenges}

The challenges we discuss do not arise in isolation but are deeply intertwined and complex. Due to the structure of intercollegiate programming and the structure of college athletics within universities, college athletic departments tend to operate in isolation from the rest of the university. Often, they predominantly function as an entity within the intercollegiate athletic system, which defines their operational structure more so than the university (Schroeder, 2010, pp. 101-102). An athletics program subculture often forms and is driven by the values of those entities that directly support college athletics (National Collegiate Athletics Association [NCAA], media associations, boosters, alumni and fans) rather than by the mission of the broader university. While supportive in various ways, these athletics-related entities may have different ideals and expectations than those of higher education. Student athletes are then caught up in the athletic subculture, which potentially undermines the student component of their role and creates ongoing distress (Hwang \& Choi, 2016).

The economistic model governing college athletics often leads to a focus on winning at all costs and generating revenue for the universities and the athletic programs. This orientation increases the potential for morally flawed decision-making within the intercollegiate athletics system. Psychological abuse may become prevalent among coaching staff and ignored by dominant actors within the system (Davis, 2020; Dodgson, 2020; Evans, et al., 2018; Myerberg, 2021; Vainisi, 2016; Williams, 2019). The athletes are treated as a means to an end for the university programs to generate revenues through increased commercialization of the sport to retain position, salary level, and power of dominant actors within the intercollegiate system.

This system of embedded moral flaws within intercollegiate athletics is particularly impactful given the developmental stage of student athletes (Perry, 1999). When athletes are immersed in a toxic subculture driven by an economistic model prioritizing winning at all costs, their moral development can be stunted (Chen et al., 2019). These findings are particularly disconcerting in that many small and medium-sized well-led and well-managed college athletics programs do provide excellent opportunities for students to develop many positive attributes including perseverance, courage, collaboration, unselfish commitment to others, time management, teamwork, sensible 
risk-taking, fair competition and physical endurance. With this backdrop, we now turn to the three specific challenges facing collegiate athletics today and analyze these issues from a humanistic leadership perspective.

\section{Challenge 1: Tension Between Amateur/Professional Status of Athletes}

According to the NCAA, a defining feature of collegiate athletics is that athletes are amateurs rather than professionals. (NCCA Amateurism, 2021). However, as extensively explored in NCAA v. Alston (2021), the reality is that the NCAA and the university members are engaged in business that generates billions of dollars of revenue for the participants, and they are effectively a monopoly. For example, in 2019 the revenues from March Madness, the annual Division I collegiate basketball championship, were $\$ 1.1$ billion (2021). The NCAA tries to maintain its identity and market advantage through naming the primary participants, the athletes, as amateurs, defined as those who are not "paid to play" but who are primarily students.

This economic tension has been part of the athletic conversation for at least 125 years as the reality of sports, particularly college football and basketball as tremendous revenue generators, is in tension with the mission of universities to provide opportunities for learners to participate in sports as part of a well-rounded education (Kirk, 2019). College athletics programs often operate according to a highly economistic model and become distinct communities isolated from the broader university environment (Schroeder, 2010, pp. 101-102). When that isolation occurs, risk for moral failure increases as the athletic department develops a subculture with values and microsocial norms in conflict with those of the broader university (Shadnam \& Lawrence, 2011, p. 395; Schroeder, 2010). That is, the economistic paradigm risks creating conditions that lead to moral failure (Shadnam \& Lawrence, 2011) in terms of the values associated with higher education and the treatment of student athletes.

In a culture driven by the economistic perspective, healthy balance is not the priority. The athletes' drive to learn, which is critical to the mission of higher education, and the drive to bond, which is critical to human connection giving purpose and meaning to life (Brown, 2010), are thwarted as university leadership explicitly or implicitly demands that the drives to acquire and defend take priority (Lawrence \& Pirson, 2015, p. 384). This state of imbalance increases the likelihood of people engaging in, ignoring, or not even recognizing behaviors that are harmful to the well-being of student athletes (Whitehead \& Senecal, 2020).
Consequence: Conflict Between Demands as an Athlete and Scholar

The realities created by a dominant economistic model break both spoken and unspoken promises made to student athletes in terms of the quality and value of their education. The first broken promise comes in terms of work-life balance. The NCAA routinely conducts surveys of student athletes whose schools are members of the NCAA. One routine survey, the Growth, Opportunities, Aspirations, and Learning of Students in College (GOALS) survey, reports on the well-being of student athletes. A summary of the NCAA's GOALS survey (2016) based on 2015 survey results indicates that the median number of hours (h.) per week spent on sport (across divisions) was about $32 \mathrm{~h}$. Division I football was reported as having the highest median of $42 \mathrm{~h}$ per week spent on their sport. From that same report, the median number of hours spent on academic work across divisions was about $39 \mathrm{~h}$. Moreover, "[s]eventy-five percent or more of student athletes in baseball, football and men's and women's track in Divisions I and II reported spending as much time on their sport in the off-season as they do in-season" (NCAA, 2016, p. 2). What that means is that student athletes are working $10 \mathrm{~h}$ a day seven days a week with little time to do anything else. For example, according to the NCAA's Mind, Body and Sport handbook, student athletes require 8-10 h of sleep to remain functional (Grander, 2014, p. 51). GOALS study findings indicate that the median number of hours of sleep per night across all divisions during on season is $6.25 \mathrm{~h}$.

The expectation for athletes to perform well in multiple areas causes them significant stress (Hwang and Choi, 2016; Whitehead \& Senecal, 2020; Yang, et al., 2007). In a recently published word cloud showing responses to what student athletes would most like to change about their experience, NCAA's (2014) Research Extra Point reports 'time' as the most frequently cited word and most of the accompanying student athlete comments related to time management difficulties and time demands. From student athlete surveys (Lu et al., 2018), one student athlete stated:

Coaches are pushing us in practice and demanding more out of us, but the team is exhausted from class all day and have stress because we have homework, group meetings and other commitments after practice that the coaches 'understand' but it doesn't change. (p. 230)

Tracking the consequences of the drive to excel in athletics and academics, NCAA survey results and student athlete studies demonstrate increases in general stress levels as a result of having inadequate time to do well in both roles (Hwang \& Choi, 2016; Lu et al., 2018; Parker et al., 2021). Madison Holleran was a freshman track runner for Penn State who committed suicide in 2014. In an interview with her father (Holleran, 2015), James Holleran attributed the 
suicide to the stress of performing two jobs, that of student and athlete. For lack of time, student athletes report more stress in the area of social relationships, academics and finances than do non-athlete students (Papanikolaou et al., 2003; Stevens et al., 2000). According to the NCAA GOALS Study (2016), "NCAA student-athletes generally reported that their expectations about college academics and time demands were accurate. However, expectations about athletics and social experience were more often reported as being less accurate" (p. 1), indicating both an opportunity and a responsibility for system actors to more clearly convey expectations in both of these areas.

\section{Consequence: Racial Disparities}

Amira Rose Davis, assistant professor of history and African American studies at Penn State University, identifies the problem of racial disparities in college sports succinctly as she writes,

In recent decades the college sports industrial complex has grown with TV deals, new stadiums, corporate sponsorships and ballooning salaries for everyone except the players. College sports is a billion-dollar industry built on the back of unpaid labor that is disproportionally Black. (2020, para 15)

While Blacks participate in many different sports, the spectator sports of football and basketball, which are the greatest source of revenue for universities, have predominately Black players. During the 2014-2015 season, Black men comprised $56.3 \%$ of players in football and $60.8 \%$ of players in basketball (Gayles, et al., 2018). Furthermore, the revenues earned by spectator sports are often used by universities to fund the remaining sports programs where players are more affluent (Maas, 2020). Finally, because of the pressures associated with athletics, the graduation success rate (GSR) for Black students in 2018 was $75 \%$ as compared to the White GSR of 91\% (Jackson, 2018). Although Black players are given the opportunity to play in these sports based upon their athletic prowess and then promised a college education, the dissatisfaction around these perceived inequities has led them to lobby for legislative changes.

\section{Resolving the Tension: Including Athletes in Revenue Sharing}

A critical change to policies governing the overall wellbeing of athletes was signaled in the Supreme Court decision, NCAA vs. Alston (2021), in which the Court affirmed that the NCAA is a monopoly and subject to antitrust laws. The Court explicitly found that "relaxing the restrictions [on paying certain academic expenses] would not blur the distinction between college and professional sports and thus impair demand (Alston, 2021, p. 4). Even though the ruling was narrow, the proverbial shot across the bow was fired as more cases concerning guaranteeing the respect and wellbeing of athletes wend their way through the lower courts.

A second sea-change concerns allowing athletes to receive compensation for use of their name/image/likeness (NIL). As of July 1, 2021, several states will allow athletes at universities in their states to receive compensation for NIL. Several other states have passed laws that will be phased in over the next several years (Clifton \& Long, 2021). The NCAA responded by enacting a NIL policy also effective July 1, 2021, allowing universities to either follow the legislation in their state or adopt their own policies consistent with existent NCAA rules (Berkowitz, 2021). In addition, pending federal legislation concerning NIL would provide uniform NIL regulations within college athletics (Murphy, 2021).

The power is now with the athletes for the very first time since amateur athletics started over 125 years ago with the founding of the Amateur Athletic Union (AAU) in 1888 (Editors, Encyclopedia Britannica). How that power gets used, how the rest of the stakeholders are folded into the conversation, can be done either through a humanistic lens with the system opportunities and pressures considered, or through the economistic lens where the athletes only consider their own financial well-being. ${ }^{1}$

As these legislative resolutions emerge, the key to having these changes help rather than hinder higher education and student athletes is to find ways to move toward a humanistic leadership approach to receiving and distributing revenue and resources. Those engaging in the drafting and implementing of new strategies have the opportunity to commit to a humanistic leadership model and use their imagination in fashioning new ethical guidelines to achieve greater work-life balance for student athletes rather than just putting band-aids on the economistic lens. If a new approach is not envisioned and implemented, the spiral of events that led to the current situation will continue, become more complex, requiring an ever-heavier legislative hand. Finally, if universities and the NCAA can find ways to regulate themselves fairly and effectively within the new context, additional laws and court intervention will not be needed.

\section{Challenge 2: Tension Between Winning and Winning Fairly}

Student athletes face a strong performance-centric set of pressures (Whitehead \& Senecal, 2020). Given the intensity of their dual roles within the university, elite student athletes

\footnotetext{
1 All recently passed and pending legislation concerning NIO is being tracked and updated daily by Business of College Sports, https://businessofcollegesports.com/tracker-name-image-and-liken ess-legislation-by-state/
} 
continually face barriers to healthy balance and well-rounded success (Derakshan \& Eysenck, 2009; NCAA, 2016). Moreover, the highly competitive culture of college athletics creates ethical tensions around the boundaries of fair play. Because of imbalance of power and relationships, college athletes are particularly sensitive to being pressured to win at all costs.

\section{Consequence: Receiving Pressure to Perform from Significant Others}

In sociology, 'significant others' are those noted to have great influence on an individual's life and self-esteem (Woelfel \& Haller, 1971). Student athletes have a number of significant others in their lives including family, team members, coaches, athletic trainers, faculty and friends who exert strong pressure for them to perform. The commitment to pleasing others presents an ongoing stressful situation that clouds judgment, reduces productivity in all areas, reduces reaction time and increases the probability of sustaining injuries (Hamlin et al., 2019; Sampson et al., 2019). In turn, injuries result in athletes being benched and facing more stress related to the possibility of losing their scholarship (should they have one) and losing future playing opportunities.

Perceived failure in meeting the expectations of any significant other leads to lower levels of self-esteem (Woelfel \& Haller, 1971). Although only an estimated 3\% of NCAA players will go pro or on to the Olympics (Cohn, 2017), parents often have unrealistic expectations of Olympic team involvement and playing professionally, and these dreams are conveyed to student athletes (Cohn, 2017). Team members want to win to enhance the team's visibility and every member's opportunity to advance in the sport (Rowatt as cited by Swindoll, 2014). Coaches and trainers want wins to avoid being fired and to enhance their visibility and future career opportunities, which are measured by how many NCAA championships they have won (Elsberry, 2010; Longman, 2012). Faculty want student athletes to do well academically as they do not want to feel pressured to give better grades than what student athletes earn or be pressured to change their grades (Miller, 2016). Finally, student athletes often feel isolated from student non-athletes and from co-curricular activities such as internships, academic competitions and study abroad experiences. In a survey exploring identity salience and role conflict, one student athlete states:

I was chosen as a finalist for an entrepreneurial competition... [but] I leave for California for a meet...I am now forced to pick one or the other and jeopardize my place on the team or my start-up that I am working on. It is an absolute head spin. (Lu et al., 2018, p. 230)
Consequence: Leveraging Power to Neutralize Athletes' Sense of Integrity

Notably, coaches have significant power over student athletes. Consider the following quote taken from a presentation by the National Sports Law Institute (Greenberg, 2018).

. . . the extraordinary power of a coach in athletic settings, with control over access to skilled-instructional time, the granting and renewal of athletics [sic] financial aid, and decisions related to playing time creates a student/coach power differential that is far greater than the differential between student and professor, potentially leading to "quid pro quo" situations. (slide 44)

The appropriate use of power becomes critical in highly competitive environments with a strong power imbalance, such as within intercollegiate athletics. The rivalry and rewards for winning increase the temptation to engage in unethical/immoral behavior by placing more focus on winning and less focus on the means of winning (Kilduff et al., 2016). That pressure increases with increased rivalry heightened by teams that compete repeatedly and historically have had closely decided contests, as is typical in intercollegiate athletics (Kilduff, et al, 2016). Consider the following narrative from a former student athlete enrolled in one of the author's ethics classes.

... when I was playing football in college, I played offensive lineman as left guard. We were playing against a team with whom we had a long rivalry history [emphasis added] at a semifinal game. . . By third quarter we were tied; my coach called me. We need to slow this guy [defensive lineman] now! The coach told me to cut block him - that will for sure lower his confidence or put him out of the game. I could not hide my moral contradiction when I heard the request. He noticed it, and immediately asked, "tell me if you can do it or not, so I can put someone in who can do it." Within a blink of an eye, I said 'yes coach'!

The play resulted in the cut blocked lineman having a severe knee injury and that team lost the game. While cut blocks are technically legal (Cubelic, 2017), the question is why a coach asked a player to deliberately injure another, especially when the chance of injury is higher with this play in a sport that already has the highest annual competition injury rate in college sports (Kerr et al., 2015). For this coach, winning was more important than ensuring the ethicality of the means of winning.

The coach missed an opportunity to strengthen the player's sense of integrity and sportsmanship by stating that the player would be benched if he failed to execute the play. The team was then rewarded with a win-an 
unfortunate lesson regarding ethical priorities. Rivalry makes college athletics a high risk environment, where maintaining an ethical mindset, one that does not infringe upon dignity, rights or holistic development, is difficult to achieve and maintain, particularly when operating from 'a winning at all costs' mentality.

The situation just described could happen because of the coach's power-a critical tool in any leadership situation and particularly so when the power differential is large, such as in the relationship between coaches and student athletes. When appropriately used, power may be strategically beneficial in achieving outcomes through coalition building, instilling motivation, and instilling self-esteem leading to positive self-worth and positive personal development. However, power misused becomes abusive, dehumanizing and debilitating, which leads to loss of dignity and well-beingall forms of moral failure especially when abuse is evident and often ignored. With a mindset of winning at all costs, inappropriately using coercive power becomes an insidious tool in achieving wins.

To complicate the situation even further, as reported within the GOALS Survey (2016), student athletes identify the relationship between them and their coach as the most important relationship they have in their role as a student athlete. As one retired student athlete reported in an interview, "We [the team] saw our coach more than we saw our parents. It sounds kind of weird, but he was like a quasifather figure... He probably knew stuff about some of us that our parents didn't even know" (Stirling \& Kerr, 2014, p. 231).

Relationship power is the most influential of all sources of power (French \& Raven, 1959). This access to relationship power gives coaches significant influence over student athletes in all areas of their lives (Stirling \& Kerr, 2008) and an abuse of power by a coach will likely result in student athletes doing what the coach wants because they not only fear punishment (French \& Raven, 1959) but they also want to maintain a close relationship with their coach to either protect or advance their position within the sport (Stirling $\&$ Kerr, 2008). And the coach who pressured his player to go against his own sense of moral integrity and fair play by demanding that the player execute a play that would likely cause injury to another player abused the power inherent in the relationship (Stirling \& Kerr, 2008).

\section{Resolving the Tension: Facilitate Positive Expressions of All Four Motivational Drives}

Succeeding in academics and athletics simultaneously requires determination and hard work. The drives to acquire and to defend facilitate performance in both areas. Yet these drives (motivations) also energize problematic behavior in highly competitive environments (Lawrence \& Pirson, 2015;
Nohria et al., 2008) such as sport. For example, Psychologist Dr. Tamara Rowatt (as cited by Swindoll, 2014) states that student athletes may be happy for another team member's success, but it is often likely they will also be envious because they wish to acquire success in their sport career, which, in some instances, leads to undermining teammates' success. The drive to bond might serve as a counterbalance to the drives to acquire and to defend, which is why many coaches who lean toward humanistic leadership encourage team members to bond. In fact, in the 2010 NCAA GOALS Survey, student athletes identified the best part of the student athlete experience as 'teammates, bonds and friendships'. College coaches have an excellent opportunity to role model and reinforce this balanced drive mindset within their daily coaching.

The drive to learn is a reflective process that satisfies human curiosity or people's need "to know, to comprehend, to believe, to appreciate, to develop understandings or representations of their environment and of themselves" (Lawrence and Nohria, 2002, p. 107). Within a balanced drive environment, student athletes will have ample opportunity to meet the drive to learn in the classroom and on the court or playing field learning from experts in both areas. However, research indicates that a lack of time for student athletes to take advantage of these learning opportunities increases anxiety and depression, which are highly detrimental to cognitive performance (learning) (Hwang \& Choi, 2016; NCAA, 2014; Tyng et al., 2017).

\section{Challenge 3: Tension Between Winking at the Mistreatment of Athletes and Ensuring Athletes are Treated with Dignity}

On June 9, 2021, we conducted a Google search using the term 'abuse in college sports'; 0.53 seconds later we had $195,000,000$ results, indicating a wide-spread interest in the topic from an array of perspectives. We share a few examples here. In a 2015 interview, Bennett Tepper from Ohio State University, an expert researcher on the topic of workplace abuse, reported that the level of abuse in college athletics is two to three times higher than that of industries such as the military, healthcare, education, financial institutions and manufacturing. Boston University women basketball players report that their coach told them they were "worthless," "too shy and backward to get anywhere in life," and "never should have been born" (Wolf, 2015, para 8). Yet the coach had a winning record and remained in her head coach role for ten years. After citing several recent college athletics tragedies, including years of abuse of student athletes occurring at Michigan State and Ohio State, Jon Valant, a fellow from the Brown Center on Educational Policy, provides an insight into the problem as he writes: 
Table 1 Overview of tensions, consequences and tension resolutions

\begin{tabular}{llc}
\hline Tensions & Consequences & Tension Resolutions \\
\hline $\begin{array}{l}\text { Economic tension between amateur versus } \\
\text { professional status of student athletes }\end{array}$ & $\begin{array}{c}\text { Conflict between demands as an athlete and } \\
\text { scholar } \\
\text { Racial disparities }\end{array}$ & $\begin{array}{c}\text { With the goal of achieving and maintain- } \\
\text { ing equity for all student athletes, include } \\
\text { student athletes in revenue sharing }\end{array}$ \\
$\begin{array}{l}\text { Defining the ethical edge between winning and } \\
\text { winning fairly }\end{array}$ & $\begin{array}{c}\text { Receiving pressure to perform from significant } \\
\text { others } \\
\text { Leveraging power to neutralize athletes' sense } \\
\text { of integrity }\end{array}$ & $\begin{array}{l}\text { With the goal of supporting healthy moral } \\
\text { development while encouraging fair play for } \\
\text { student athletes, facilitate positive expres- } \\
\text { sions of all four motivational drives (life } \\
\text { balance) at all levels within the system }\end{array}$ \\
$\begin{array}{ll}\text { Winking at the mistreatment of athletes (to } \\
\text { extract performance) versus ensuring athletes } \\
\text { are treated with dignity }\end{array}$ & Risks to student athlete well-being & $\begin{array}{c}\text { With the goal of achieving and maintaining } \\
\text { student athlete holistic development and } \\
\text { well-being, balance opportunities for com- } \\
\text { petition and education }\end{array}$
\end{tabular}

... today's premier college sports programs are largely composed of, and surrounded by, individuals with little incentive to uncover or address misconduct. And too often, those individuals have chosen to protect their programs before they protect victims of their programs' abuse. (Valant, 2018, para. 2)

\section{Consequence: Believing Abuse is a Condition of Participation}

Considerable evidence indicates that student athletes face risks to their well-being due to patterns of emotional, psychological and physical abuse (Lopez et al., 2020; Stirling \& Kerr, 2008, 2014; Tepper, 2000, 2015). Periods of prolonged threat may lead to reduced performance and adverse health for student athletes who have been emotionally abused by coaches and feel threatened (Lopez et al., 2020). Even more insidious than the abusive coaching behavior itself is the prevalence of student athletes accepting and even promoting the behavior as 'effective' coaching because it creates the 'mental toughness' needed to win. To illustrate, Tom Rice, the former Rutgers men's basketball coach was fired for his explosive behavior on the court during the 2013 season. His behavior was so outrageous that a video of one episode went viral and drew wide-spread attention (BSOTV, 2013). By all accounts the behavior captured on video was not atypical of Rice's coaching style. Yet subsequent to Rice's removal, one Rutgers player was quoted as saying, "We don't want a white-collar, clean-cut guy. We want somebody who understands us and will push us every day, like Rice did" (Associated Press, 2013). The player's statement reflects the unfortunate assumption that abusive coaching tactics are the only effective mechanism for challenging and improving player performance.

In examining the systemic failure of the United States Olympic Committee (USOC), U.S.A. Gymnastics and Michigan State University (MSU) to hold Dr. Nassar accountable for years of sexual assault of gymnasts, the MSU athletic department and the USOC regularly broke their own rules in order to avoid damaging their reputation in the community (Associated Press, 2021; Evans et al., 2018). Likely one of the most difficult decisions occurred when coaches delayed reporting the misconduct because gymnastics scoring is so subjective that they were afraid raising concerns would jeopardize their own students' opportunities to win at meets, which could also jeopardize their coaching positions (2018). In response to this scandal and others, in May of 2020, the NCAA put in place new regulations requiring both athletes and athletic programs to disclose any investigations or disciplinary actions concerning abuse (NCAA Board of Governors, 2020).

These examples illustrate how dominant actors within social systems fail to hold people accountable for their inappropriate acts because in the economistic model, the drive to defend (reputation, revenue, competitive advantage, etc.) is more important than exercising the moral courage to call out inappropriate behavior and hold violators accountable leading to the belief that abuse is a condition of practice.

\section{Consequence: Risks to Student Athlete Well-Being}

Evidence indicates that participating in college athletics at the elite level (particularly within the NCAA Division I spectator sports of men's football and basketball) puts student athletes at risk for unhealthy levels of emotional distress and psychological strain making them more prone to physical injury when practicing their sport (Putukian, 2016). The Center for Disease Control (CDC) reports the number of injuries by sport that NCAA student athletes sustained during practice and competition over a five-year period, academic years 2009-2010 through 2013-2014, as $1,053,370$ or 210,674 per year on average (Kerr et al., 2015 , Table 1 ). Nearly $22 \%$ of the injuries require seven or more days to return to full participation in the sport (Kerr et al, 2015). To compound the problem, nearly $20 \%$ of athletic directors reported that a coach played a student athlete 
where it was medically determined that the athlete should not play due to an existing injury, thereby putting these student athletes at a higher risk for more severe injuries (Radelat, 2019, para 15). Psychological stress increases muscle tension and attention deficits, which can then lead to increases in physical injury. In turn, physical injury can lead to further anxiety and depression (Putukian, 2016). As a result of more serious injuries, some student athletes lose their scholarships the following year, and they may also lose their university provided health care insurance coverage (Radelat, 2019). Finally, student athletes lose their self-identity, which lowers their self-esteem when prolonged recovery from injuries occurs (Dean, 2018; Lockhart, 2010).

This spiral of events undermines student athletes' ability to benefit not only in their athletic role, but also in their academic role. In a study of stressors for student athletes, academic anxiety is reported as the highest stressor (Hwang $\&$ Choi, 2016). Moreover, several research findings on student athletes point to a direct relationship between unhealthy emotional distress and risk to well-being; abusive environments also compromise well-being (Hwang \& Choi, 2016; Lopez et al., 2020; Riemer et al., 2000; Stirling \& Kerr, 2014; Yukhymenko-Lescroat et al., 2015.) The many forms of abuse reported by student athletes (Tepper, 2015) further accentuate the risk of physical injury.

To date, GOALS Surveys have taken place in 2006, 2010, 2015 and 2019. When compared to the previous GOALS surveys, with over 21,000 student athletes self-reporting from over 600 participating schools across NCAA divisions I, II and III, the 2015 NCAA GOALS Survey as reported in 2016 revealed an increase in student athlete levels of anxiety and depression, with about $30 \%$ of respondents stating that "they have been intractably overwhelmed during the past month" (2016, p. 4).

The COVID-19 epidemic that impacted three academic semesters between 2020 and 2021 significantly increased self-reporting of student athlete mental health problems. Responses from NCAA's Student Athlete COVID-19 WellBeing Survey $(n=37,658)$ indicate that the rate of mental health concerns self-reported within the month of May 2020 were $150 \%$ to $250 \%$ higher than what had been historically reported by NCAA student athletes in the American College Health Association's National College Health Assessment (NCAA Student Athlete COVID-19 Well-being Survey, 2020, slide 8).

Another area of concern is psychological abuse, which has been linked to mental health issues, including increased anxiety, depression and lowered self-esteem (Lopez et al., 2020). Temper's workplace abuse scale was used to measure self-reported abuse for student athletes because the criteria that define the relationship between organizations and employees are very much aligned to the relationship between student athletes and their coaches (Tepper, 2015). Given the number of recently reported instances of student athlete abuse featured in the media (Davis, 2020; Dodgson, 2020; Evans, et al., 2018; Greene, 2021; Myerberg, 2021; Vainisi, 2016; Williams, 2019) and studied in current sports research (Adams \& Kavanagh, 2020; Kavanagh et al., 2020; Kerr \& Kerr, 2020; Lopez et al., 2020; McMahon \& McGannon, 2020; Nite \& Nauright, 2020; Roberts et al., 2020), the problem appears to continue.

\section{Resolving the Tension: Balance Opportunities for Competition and Education}

Approaching college athletics with a balanced drive mindset is key to practicing humanistic leadership (Lawrence \& Pirson, 2015) and to aligning with the goals of higher education. Notably, motivational drive imbalance leads to decreased well-being even for those who are most driven by the predominant drive in place. Because leadership is also critical in creating, supporting and role modeling issues of morality (Lawrence \& Pirson, 2015; Melé, 2016; Ogunfowora, 2014; Shadnam \& Lawrence, 2011; Waddock, 2016), humanistic leadership provides a powerful learning experience for student athletes when those in leadership are consistently good role models. Measuring behaviors and strategies against the values and principles of a humanistic leadership model, which aligns with the ideals of higher education, is one of the most viable ways to keep the promises made to student athletes during recruitment and as stated within the university mission and values statements.

In addition to supporting educational opportunities connected to academic subject matter, college athletics programs can foster learning and development through athletic training methods that are consistent with humanistic leadership. For example, although empirical research is limited at this time, some studies have shown that humanistic leadership is effective in coaching behavior.

One qualitative case study conducted by Jenny and Hushman (2014) involved a men's NCAA Division I distance running coach. The coach consistently practiced humanistic leadership (often described in the sports literature as athletecentered coaching versus coach-centered coaching) except in the area of planning interval and tempo workouts. As a result of the coach demonstrating democratic, interactive, collaborative and empathetic behaviors, the players demonstrated self-agency and confidence in making decisions that were best for the team. In one area, interval and tempo workouts, the coach used a more authoritative approach. Notably, for these workouts, athletes became dependent on the coach for direction. The findings suggest that the more the coach used an athlete-centered approach, the more confident athletes became with independent decision-making, which is aligned 
with the humanistic ideal of treating individuals with dignity by empowering them to achieve personal goals.

Two empirical studies (Falcão, et al., 2020; Falcão and Bloom, 2017) evaluated the influence that humanistic coach training had on athletes' developmental outcomes. The 2017 study trained athletic coaches in humanistic coaching principles; the coaches then applied these principles to their coaching of youth basketball teams (players ages 12-17) whose players came from lower socio-economic communities in Canada. The coaches noted positive outcomes in the athletes in the areas of autonomy, communication, motivation and willingness to help teammates. In the 2020 study, applying an experimental design, 12-17 year old athletes from low socio-economic communities who were in the treatment group (applied humanistic coach training) showed stronger connection to the coach and engaged in less antisocial behaviors than the control group (no coach training occurred).

The final study reviewed was a multi-case instrumental study conducted in the Philippines and New Zealand (Walters et al., 2018) where sports programs were implemented with a humanistic coaching philosophy with the goals to gain insight on how sport might be used to engage and build relationships with community and to enhance the selfesteem and confidence of students who were at risk and/or in conflict with the law. The age of participants was predominantly 17-25. Prior to implementation of the humanistic sports programming, the traditional paradigm was that sports were an outcome driven competition with a goal of winning at all costs. However, approaching sports with a balanced drive mindset that aligned with core humanistic principles led to a transformative change where sports participants and non-participants began to view sports as inclusive, fun and community oriented. Refer to Table 1 for an overview of tensions, consequences and tension resolutions.

\section{Strategies for Success}

We assert that humanistic leaders within college athletics could engage in three strategies for success in meeting the above-outlined challenges going forward: (1) role modeling and providing information about what behaviors comprise humanistic leadership within the moral community; (2) putting structural supports in place to mitigate against unethical behaviors that are more likely to occur when perfect storm dynamics are embedded in the subculture of collegiate sports due to the nature of its operations and (3) holding those who violate ethical norms accountable for their actions.

\section{Strategy 1: Be an Effective Role Model}

Leadership behavior is one key influence on organizational culture. Leader actions and decisions communicate values and priorities more convincingly than any mission statement or formal set of rules (Schein, 2008). This role modeling helps to educate people about what behaviors will and will not be accepted (Henning, 2005). When we have subcultures (i.e., intercollegiate athletics) with norms that differ from the mainstream or preferred culture (i.e., inclusive higher education), it opens the door for actors within those subcultures to be treated outside of the range of acceptable behaviors for the culture as a whole (Bazerman \& Tenbrunsel, 2011).

Having dominant actors within higher education role model their commitment to others' well-being through humanistic leadership also serves to positively influence students (Ogunfowora, 2014) who will have future opportunities to lead within their communities and workplaces. In high stress environments such as college athletics, we suggest that the beliefs and behaviors that flow from humanistic leadership hold promise for human flourishing and shared well-being. With clear identification and ongoing discernment of humanistic values transpiring through healthy social interaction occurring at and between all levels, holistic student well-being is more likely to occur.

\section{Strategy 2: Put Structural Supports in Place}

This strategy starts with university leadership being aware of the likely imbalances that may occur in the subculture of intercollegiate sports, which is prone to isolation due to its operational differences. Although universities do a good job of putting information prohibiting inequalities and abuses in their handbooks, they may not provide the necessary anchors for reminding people in all areas of campus that these behaviors are unacceptable. While students "may not like to be judged or to feel judged, they do search for tools and frameworks to help them make good decisions about all sorts of things, including relationships, friendships, and sex, how they party, and even how they drink" (Freitas, 2018, p. 138). The resolution is thus structural; drawing on its stated values, the university can employ an array of visible techniques, including appropriate hiring, appropriate reporting structures and appropriate role modeling from dominant actors, to anchor the dignity and respect for all humans as a core moral expectation within every department of the university (Bazerman \& Tenbrunsel, 2011). As the moral community incorporates multiple opportunities for social exchange into its culture that demonstrate respect for all entities within the system, holistic student athlete well-being is more likely to occur. 


\section{Strategy 3: Hold People Accountable}

The first step in holding people accountable is learning how to speak up when we see another acting inappropriately. Gentile (2010) talks about the importance of "building the confidence and skills and the scripts that enable us to do so effectively and with the least amount of angst" (p. 1). People often feel uncomfortable confronting unacceptable behavior, especially when they perceive differences in power, and so it continues until real damage is done. Student athletes often do identify abusive practices by dominant actors and it is critically important for leadership at all levels to act upon that information expediently. More insidious, however, is not holding someone accountable because a personal agenda will not be fulfilled. Such were the circumstances in the cases of Michigan State and Ohio State, which were identified as extreme examples earlier in this work. We are encouraged, however, by athletic organizations and the NCAA taking increasingly strong stands and putting in place strategies to protect athletes (NCAA Board of Governors, 2020). As the system's leadership consistently holds people accountable for violating ethical norms (e.g. student athlete dignity) even when that action may risk financial performance, holistic student athlete well-being is more likely to occur. Please see Table 2 for an overview of strategies, strategic actions and potential benefits.

\section{Discussion}

The purpose of this work was to explore the social system of intercollegiate athletics through the lens of humanistic leadership and education to enhance the lived experience and holistic development of student athletes by lessening the inequalities and abuses occurring within the system. From that exploration, we suggest that a humanistic leadership model rather than an economistic one might achieve a more equitable community where student athletes have more freedom to engage in holistic learning similar to that of nonstudent athletes, which supports the mission and values of higher education. We included examples of how a humanistic leadership approach has been successful in student athlete settings.

\section{Practical Implications}

Dominant actors responsible for the shaping of the ethical climate and enforcing the moral norms on a university campus are encouraged to begin by understanding the ongoing dynamics within intercollegiate athletics and how those dynamics may easily lead to less than perfect decisionmaking and the higher probability of moral failure. Legal and legislative interventions may have been avoided if the 
NCAA and those in leadership roles within the universities consistently demanded that all student athletes be treated with dignity and respect (Mikula, 1986; Miller, 2001). Moreover, college students describe everyday injustices as violations of promises, cutting to the core of ethical leadership that depends on a relationship of trust (Mikula, 1986; Mikula et al., 1990).

Because moral disengagement (Bandura, 2002) occurs at both individual and collective levels within social systems, in addition to demanding humane standards, safeguards should be built into systems to uphold compassionate behavior and to renounce cruelty (p. 101). Importantly, defining, strengthening, and enforcing the expectations for ethical behavior within the moral community of intercollegiate athletics from what it is to what it could be requires that the dominant actors within that community be convinced that the change is needed. It is far easier to persuade a moral community that corrective action is needed with pressure from society-at-large as well as demands from internal stakeholders (Berkowitz, 2021). This dual source of pressure is seen in the changes within college athletics. For example, the breach in the dam awarding athletes rights to their name/ image/likeness came from state legislation and the judicial system. These changes were driven by members of the community bringing forward cases of ethical misconduct as well as those within the system who were dissatisfied with the treatment of student athletes persistently voicing their concerns to politicians and the media regarding the ongoing problems (Dellenger, 2021). Consistent attention to rectifying and preventing systemic sources of mistreatment from within college athletics would help to avoid the need for external judicial action in the future.

College athletics is an integral part of U.S. higher education and U.S. culture. At its best, college athletics enhances the academic experience of athletes by promoting teamwork, time management and physical endurance. However, to advance and protect the higher education experience for all students, the system of intercollegiate athletics must be seen primarily as an educational endeavor (Mitten et al., 2009). We see the practice of humanistic leadership throughout the system of intercollegiate athletics as one way that this goal might be accomplished while retaining the benefits of intercollegiate athletics.

\section{Future Research}

The current situation within intercollegiate athletics as described within this work offers multiple opportunities for future research in business ethics. Impending regulation has already created a sense of urgency within the collegiate athletic system, which generally drives collaboration and commitment to change (Kotter, 2012). Considering ethics as part of the overall change process is vitally important (Gerdy, 2001; Lapchick, 2001; Seib, 2001; Teaff, 2001). In the context of college athletic departments, areas where critical ethical studies are necessary might be reflected in the following questions. "How does the change we are considering support the overall mission and values of higher education?" "How might the system enact regulatory change in ways that better unite college athletics with the university as a whole?" "What structural changes are needed within the intercollegiate athletics system to advise, support, communicate and enact change? "Who are the dominant actors that should be embedded within that structure in order to promote and sustain a balanced motivational drive mindset?" "How does the predicted short and long term effect of any intended change within intercollegiate athletics impact the well-being of student athletes?" and "How does such an intended change preserve the dignity and advance the health and well-being of the system and society as a whole?".

\section{Conclusion}

Athletic systems will perennially face the challenges of harmonizing values in tension based on the dual responsibilities they have for supporting student athletes while forwarding their overall education. As the three challenges explored in this paper, (1) navigating the tension between claiming college athletes are amateurs rather than professionals, (2) defining the ethical edge between winning and winning fairly, and (3) moderating the insatiable drive to win while protecting student athlete well-being, are reframed from solely individual problems to systemic issues, opportunities to meaningfully intervene come into focus.

Intervening in the face of moral failure requires thoughtful intentionality. The positive impact that commitment would have on the lives of student athletes and the moral community of intercollegiate athletics makes the effort worthwhile. By so doing, the overarching moral obligation to create a holistic and safe learning environment for all students, including student athletes, is met and universities can model strategies for moral excellence and human flourishing that will inform the lives of learners well past graduation and well past the height of their athletic prowess.

Acknowledgements The authors wish to express thanks to Dr. Paul McInerny for his insightful feedback on drafts of this manuscript.

Funding This research was not funded.

\section{Declarations}

Conflict of interest There are no conflicts of interest to declare. 


\section{References}

Adams, A., \& Kavanagh, E. (2020). The capabilities and human rights of high performance athletes. International Review for the Sociology of Sport, 55(2), 147-168. https://doi.org/10.1177/2F101 2690218791139

Associated Press. (2021 June 17). How the Larry Nassar scandal has affected MSU, others. https://www.theoaklandpress.com/2020/ 08/04/how-the-larry-nassar-scandal-has-affected-msu-others/

Bandura, A. (2002). Selective moral disengagement in the exercise of moral agency. Journal of Moral Education, 31(2), 101-119.

Bazerman, M. H., \& Tenbrunsel, A. E. (2011). Blind spots: Why we fail to do what's right and what to do about it. Princeton University Press.

Berkowitz, S. (2021 June 28). NCAA Council recommends name, image and likeness policies should be up to schools in states without law beginning Thursday. USA Today.

Britannica, T. Editors of Encyclopedia. (1998, July 20). Amateur Athletic Union of the United States. Encyclopedia Britannica. https://www.britannica.com/topic/Amateur-Athle tic-Union-of-the-United-States

Brown, B. (2010). The gifts of imperfection: Let go of who you think you are supposed to be and embrace who you are. Center City, $\mathrm{MN}$ : Hazelden.

BSOTV. (2013 April 2). Mike Rice bullying players at practice [Video]. https://www.youtube.com/watch?v=Mtf6eWtGWh0

Chen, Y., Buggy, C., \& Kelly, S. (2019). Winning at all costs: a review of risk-taking behaviour and sporting injury from an occupational safety and health perspective. Sports Med Open. https://doi.org/ 10.1186/s40798-019-0189-9\#citeas

Clifton, G. E., \& Long, J. G. (2021). State name, image, and likeness laws with July 1 st effective dates continue to grow. National Law Review, Vol. XI (127).

Cohn, P. (2017). How do parental expectations hurt young athletes? Kids in sports. https://www.youthsportspsychology.com/youth_ sports_psychology_blog/how-do-parental-expectations-hurtyoung-athletes/

Cole, J., \& Martin, A. J. (2018). Developing a winning sport team culture: Organizational culture in theory and practice. Sport in Society, 21(8), 1204-1222. https://doi.org/10.1080/17430437. 2018.1442197

Cortez-Sanchez, J. D. (2018). Mission statements of universities worldwide-Text mining and visualization. OmniaScience, 14(4), 584-603.

Cubelic, C. (2017 October 4). Fired up with Cole Cubelic: Cut blocking controversy. Alabama Crimson Tide on AL.com [Video]. https:// www.youtube.com/watch? $\mathrm{v}=$ TrNSof-Lu1s

Davis, A. R. (2020, August 11). Black college athletes are rising up against exploitative system they labor in. Washington Post. https://historynewsnetwork.org/article/176824

Dean, N. A. (2018). "Just Act Normal": Concussion and the (Re)negotiation of Athletic Identity. Sociology of Sport Journal, 36(1), 1-33. https://doi.org/10.1123/ssj.2018-0033

Dellenger, R. (June 28, 2021). NCAA leaders still divided on NIL legislation as solution set to pass Wednesday. Sports Illustrated. https://www.si.com/college/2021/06/28/ncaa-leadership-divid ed-nil-legislation

Derakshan, N., \& Eysenck, M. W. (2009). Anxiety, processing efficiency, and cognitive performance: New developments from attentional control theory. European Psychologist, 14(2), 168176. https://doi.org/10.1027/1016-9040.14.2.168

Dodgson, L. (2020 October 30). Female college athletes from across the US say they've been bullied, manipulated, and psychologically abused by their coaches. Insider. https://www.insider.com/ players-say-psychological-abuse-college-women-sports-coach es-2020-7

Elison, J., \& Partridge, J. A. (2012). Relationships between shamecoping, fear of failure, and perfectionism in college athletes. Journal of Sport Behavior, 35(1), 19-39.

Elsberry, C. (2010 January 24). Pressure on college coaches to win never ends. ctpost. https://www.ctpost.com/basketball/article/ Pressure-on-college-coaches-to-win-never-ends-333933.php

Evans, T., Alesia, M. \& Kwiatkowski, M. (2018 Feb 8). A 20-year toll: 368 gymnasts allege sexual exploitation. IndyStar. https://www. indystar.com/story/news/2016/12/15/20-year-toll-368-gymnastsallege-sexual-exploitation/95198724/

Falcão, W. R., \& Bloom, G. A. (2017). Coaches' experiences learning and applying the content of a humanistic coaching workshop in youth sport settings. International Sport Coaching Journal, 4, 279-290. https://doi.org/10.1123/iscj.2O17-0027

Falcão, W. R., Bloom, G. A., \& Sabiston, C. M. (2020). The impact of humanistic coach training on youth athletes' development through sport. Sports Science \& Coaching, 15(5-6), 610-620. https://doi.org/10.1177/1747954120933975

Fransen, K., McEwan, D., \& Sarkar, M. (2020). The impact of identity leadership on team functioning and well-being in team sport: Is psychological safety the missing link? Psychology of Sport and Exercise, 51, 101763. https://doi.org/10.1016/j.psychsport. 2020.101763

Freitas, D. (2018). Consent on campus: A manifesto. Oxford University Press.

French, J. R., \& Raven, B. (1959). The bases of social power. In D. Cartwright (Ed.), Studies in social power (pp. 150-164). Institute for Social Research, University of Michigan.

Gayles, J. G., Comeaux, E., Ofoegbu, E., \& Grummert, S. (2018). Neoliberal capitalism and racism in college athletes: Critical approaches for supporting student athletes. New Directions for Student Services, 2018(163), 11-21. https://doi.org/10.1002/ss. 20266

Gearity, B. T., \& Murray, M. A. (2011). Athletes' experiences of the psychological effects of poor coaching. Psychology of Sport and Exercise, 12(3), 213-221. https://doi.org/10.1016/j.psychsport. 2010.11 .004

Gentile, M. C. (2010). Giving voices to values: How to speak your mind when you know what is right. Yale University Press.

Gerdy, J. R. (2001). Have college athletics become destructive in America? Professional Ethics, 9(2), 67-78.

Grander, M. (2014). Sleeping disorders. In G. T. Brown (Ed.), Mind, body and sport: Understanding and supporting student-athlete mental wellness (pp. 51-53). NCAA.

Greenberg, M. J. (2018 June 26). Zero tolerance-Abuse must end in college athletics. [Ethical issues in sports and entertainment]. National Sports Law Institute. Milwaukee, WI, United States. https://www.greenberglawoffice.com/zero-tolerance-abuse-mustend-in-college-athletics/

Greene, L. (2021 July 30). The medals keep piling up. But at what cost? Sports Illustrated: Daily Cover. https://www.si.com/olymp ics/2021/07/30/can-usa-gymnastics-be-saved-daily-cover

Hamlin, M. J., Wilkes, D., Eliot, C. A., Lizamore, C. A., \& Kathiravel, Y. (2019). Monitoring training loads and perceived stress in young elite university athletes. Frontiers in Physiology, 10, 1-12.

Haugaard, M., \& Clegg, S. R. (2009). Why power is the central concept of the social sciences. In M. Haugaard \& S. R. Clegg (Eds.), Sage handbook of power (pp. 1-24). Sage Publications Ltd.

Henning, B. G. (2005). The ethics of creativity: Beauty, morality, and nature in a processive cosmos. University of Pittsburgh Press.

Holleran, J. (2015 March 26). Real sports with Bryant Gumbel: Depression in college athletes web extra \#2(HBO Sports). [Video]. https://www.youtube.com/watch? $\mathrm{v}=\mathrm{onDbHcooSq} 8$ 
Hwang, S., \& Choi, Y. (2016). Data mining in the exploration of stressors among NCAA student athletes. Psychological Reports, 119(3), 787-803. https://doi.org/10.1177/2F0033294116674776

Jackson, D. Z. (2018 December 26). NCAA needs a reality check when it comes to grad rates for black athletes. The Undefeated. https:// theundefeated.com/features/grad-rates-for-black-athletes-ncaaneeds-a-reality-check/

Jenny, S. E., \& Hushman, G. F. (2014). A case study of a successful men's NCAA division i distance running coach: To what extent is decision-making humanistic? The Sport Journal, 22, 1-19.

Kavanagh, E., Adams, A., Lock, D., Stewart, C., \& Cleland, J. (2020). Managing abuse in sport: An introduction to the special issue. Sport Management Review, 23(1), 1-7. https://doi.org/10.1016/j. smr.2019.12.002

Kerr, R., \& Kerr, G. (2020). Promoting athlete welfare: A proposal for an international surveillance system. Sport Management Review, 23, 95-103. https://doi.org/10.1016/j.smr.2019.05.005

Kerr, Z. Y., Marshall, S. W., Dompier, T. P., Corlette, J., Klossner, D. A. \& Gilchrist, J. (2015). College sports-related injuries-United States, 2009-10 through 2013-14 academic years. Centers for disease control and prevention (CDC). https://www.cdc.gov/ $\mathrm{mmwr} /$ preview/mmwrhtml/mm6448a2.htm

Kilduff, G. J., Galinsky, A. D., Gallo, E., \& Reade, J. J. (2016). Whatever it takes to win: Rivalry increases unethical behavior. Academy of Management Journal, 59(5), 1508-1534.

Kirk, J. (2019 October 4). The endless argument at the center of college football. Banner Society. https://www.bannersociety.com/2019/ 10/4/18716003/college-football-amateurism-history

Kotter, J. P. (2012). Leading change. Harvard Business Review Press.

Lapchick, R. (2001). Ethics in sports: Equal opportunity and the exploitation of athletes. Professional Ethics, 9(2), 41-51.

Lawrence \& Nohria. (2002). Driven: How human nature shapes our choices. Jossey-Bass.

Lawrence, P. R., \& Pirson, M. (2015). Economistic and humanistic narratives of leadership in the age of globality: Toward a renewed Darwinian theory of leadership. Journal of Business Ethics, 128, 383-394. https://doi.org/10.1007/s10551-014-2090-2

Lockhart, B. D. (2010). Injured athletes' perceived loss of identity: Educational implications for athletic trainers. Athletic Training Educational Journal, 5(1), 26-31. https://doi.org/10.4085/1947380X-5.1.26

Longman, J. (2012 November 28). Firing a coach, at a price, with little evidence the move pays off. The New York Times. https://www. nytimes.com/2012/11/29/sports/ncaafootball/time-runs-out-butnot-the-money-in-college-football-coaches-firings.html

Lopez, Y. P., Dohrn, S., \& Posig, M. (2020). The effect of abusive leadership by coaches on Division I student-athletes' performance: The moderating role of core self-evaluations. Sport Management Review, 23, 130-141. https://doi.org/10.1016/j.smr.2019.07.001

Lu, L. D., Heinze, K. L., \& Soderstrom, S. (2018). Playing multiple positions: Student-athlete identity salience and conflict. Journal of Intercollegiate Sport, 11, 214-241.

Maas, S. (2020). Revenue redistribution in big-time college sports. The Digest, No. 11. https://www.nber.org/digest-202011/reven ue-redistribution-big-time-college-sports

McDonald, P. (2012). Workplace sexual harassment 30 years on: A review of the literature. International Journal of Management Reviews, 14, 1-17. https://doi.org/10.1111/j.1468-2370.2011. 00300.x

McMahon, J., \& McGannon, K. R. (2020). I hurt myself because it sometimes helps": Former athletes' embodied emotion responses to abuse using self-injury. Sport, Education and Society, 26(2), 161-174. https://doi.org/10.1080/13573322.2019.1702940

Mehta, S. (2019). Relationship between workload and throwing injury in varsity baseball players. Physical Therapy in Sport, 40, 66-70.
Melé, D. (2016). Understanding Humanistic Management. Humanist Management Journal, 1, 33-55.

Mikula, G. (1986). The experience of injustice. Towards a better understanding of its phenomenology. In H. W. Bierhoff, R. L. Cohen, \& J. Greenberg (Eds.), Justice in social relations (pp. 103-123). New York: Plenum.

Mikula, G., Petri, B., \& Tanzer, N. (1990). What people regard as unjust: Types and structures of everyday experiences of injustice. European Journal of Social Psychology, 20, 133-149.

Miller, D. T. (2001). Disrespect and the experience of injustice. Annual Review of Psychology, 52, 527-553.

Miller, G. (2016, September 29). Here's my advice to college professors being pressured to change student-athletes' grades. HuffPost. https://www.huffpost.com/entry/heres-my-advice-to-colleg_b_ 8208302

Mitten, M. J., Musselman, J. L., \& Burton, B. W. (2009). Commercialized intercollegiate athletics: A proposal for targeted reform consistent with American cultural forces and marketplace realities. Journal of Intercollegiate Sport, 2, 202-232.

Murphy, D. (2021 June 21). Everything you need to know about the NCAA's NIL debate. ESPN. https://www. espn.com/college-sports/story/_/id/31086019/every thing-need-know-ncaa-nil-debate

Myerberg, P. (2021 March 30). Kim Mulkey remarks on COVID19 testing in NCAA tournaments isn't first time she has raised eyebrows. USA Today. https://www.usatoday.com/story/sports/ ncaaw/2021/03/30/baylor-kim-mulkey-covid-19-testing-infla mmatory-moments/7061460002/

National Collegiate Athletic Association v. Alston et al., 594 U.S. ---. (2021). https://www.supremecourt.gov/opinions/20pdf/20-512_ gfbh.pdf

NCAA Amateurism. (2021). https://www.ncaa.org/student-athletes/ future/amateurism

NCAA. (2010). Examining the student-athlete experience through the NCAA

NCAA. (2011). GOALS and SCORE studies [Conference presentation]. NCAA 2011 Convention, San Antonio, TX, United States. https://www.ncaa.org/sites/default/files/Goals10_score96_final_ convention2011_public_version_01_13_11.pdf

NCAA. (2016). GOALS Study of the Student Athlete Experience. https://www.ncaa.org/sites/default/files/GOALS_2015_summa ry_jan2016_final_20160627.pdf

NCAA Board of Governors. (2020 May 1). Board of Governors expands sexual violence policy. https://www.ncaa.org/about/ resources/media-center/news/board-governors-expands-sexualviolence-policy

NCAA Research Extra Point. (2014). If I Could Change One Thing about My Student-Athlete Experience ... http://www.ncaa.org/ about/resources/research/if-i-could-change-one-thing-about-mystudent-athlete-experience

NCAA Student Athlete COVID-19 Well-being Survey. (2020). https:// ncaaorg.s3.amazonaws.com/research/other/2020/2020RES_ NCAASACOVID-19SurveyPPT.pdf

Nite, C., \& Nauright, J. (2020). Examining institutional work that perpetuates abuse in sport organizations. Sport Management Review, $23,117-129$.

Nohria, N., Groysberg, B. \& Lee-Eling, L. (2008). Employee motivation: A powerful new model. Harvard Business Review, 1-9. http://www.ippn.ie/images/stories/EndaMcNulty_EmpolyeeMo tivationAPowerfulNewModel.pdf

Ogunfowora, B. (2014). It's all a matter of consensus: Leader role modeling strength as a moderator of the links between ethical leadership and employee outcomes. Human Relations, 67(12), 1467-1490. https://doi.org/10.1177/0018726714521646

Papanikolaou, Z., Nikolaidis, D., Patsiaouras, A., \& Alexopoulos, P. (2003). Commentary: The freshman experience: High stress-low 
grades. Athletic Insight: The Online Journal of Sport Psychology, 5(4). https://www.athleticinsight.com/Vol5Iss4/Commentary.htm

Parker, P. C., Perry, R. P., Coffee, P., Chipperfield, J. G., Hamm, J. M., Daniels, L. M., \& Dryden, R. P. (2021). The impact of studentathlete social identity on psychosocial adjustment during a challenging educational transition. Psychology of Sport and Exercise. https://doi.org/10.1016/j.psychsport.2021.101979

Perry, W. G., Jr. (1999). Forms of Ethical and Intellectual Development in the College Years: A Scheme. Jossey-Bass.

Pirson, M. (2017). Humanistic management: Protecting dignity and promoting well-being. New York, NY: Cambridge University Press.

Pluhar, E., McCracken, C., Griffith, K. L., Christino, M. A., Sugimoto, D., \& Meehan, W. P., III. (2019). Team sport athletes may be less likely to suffer anxiety or depression than individual sport athletes. Journal of Sport Science and Medicine, 18, 490-496.

Putukian, M. (2016). The psychological response to injury in student athletes: A narrative review with a focus on mental health. British Journal of Sports Medicine, 50, 145-148. https://doi.org/10. 1136/bjsports-2015-095586

Radelat, A. (2019 December 16). Murphy takes on NCAA on college sports injuries. The CT Mirror. https://ctmirror.org/2019/12/16/ murphy-takes-on-ncaa-on-college-sports-injuries/

Riemer, B. A., Beal, B., \& Schroeder, P. (2000). The influences of peer and university culture on female student athletes' perceptions of career termination, professionalization, and social isolation. Journal of Sport Behavior, 23(4), 364-378.

Roberts, V., Soho, V., \& Grant, F. (2020). Organizational factors and non-accidental violence in sport: A systematic review. Sport Management Review, 23, 8-27. https://doi.org/10.1016/j.smr. 2019.03.001

Sampson, J. A., Murray, A., Williams, S., Sullivan, A., \& Fullagar, H. H. K. (2019). Subjective wellness, acute: Chronic workloads, and injury risk in college football. Journal of Strength and Conditioning Research, 33(12), 3367-3373.

Schein, E. H. (2008). Creating and managing a learning culture: The essence of leadership. In J. Gallos (Ed.), Business leadership (pp. 362-369). Jossey-Bass.

Schroeder, P. J. (2010). A model for assessing organizational culture in intercollegiate athletic departments. Journal of Issues in Intercollegiate Athletics, 3, 98-118.

Seib, P. (2001). Media coverage and the college student-athlete: Ethical perspectives. Professional Ethics, 9(2), 61-66.

Shadnam, M. \& Lawrence, T. B. (2011). Understanding widespread misconduct in organizations: An institutional theory of moral collapse. Business Ethics Quarterly, 21(3): 379-407. https:// www.jstor.org/stable/41304438

Stevens, R. E., London, D. L., Yow, D. A., Bowden, W. W., \& Humphrey, J. H. (2000). Stress in College Athletics: Causes, Consequences, Coping. The Haworth Half-Court Press. https://doi.org/ $10.4324 / 9781315043593$

Stirling, A. E., \& Kerr, G. A. (2008). Defining and categorizing emotional abuse in sport. European Journal of Sport Science, 8, 173-181. https://doi.org/10.1080/17461390802086281

Stirling, A. E., \& Kerr, G. A. (2014). Initiating and sustaining emotional abuse in the coach-athlete relationship: An ecological transactional model of vulnerability. Journal of Aggression,
Maltreatment \& Trauma, 23(2), 116-135. https://doi.org/10. 1080/10926771.2014.872747

Swindoll, J. (2014 May 2). Athletes should bench envy of teammates. Baylor Lariat. https://baylorlariat.com/2014/05/02/athletesshould-bench-envy-of-teammates/

Teaff, G. (2001). Is there room for ethics in college sports? Professional Ethics, 9(2), 31-40.

Tepper, B. J. (2000). Consequences of abusive supervision. Academy of Management, 43(2), 178-190. https://doi.org/10.2307/1556375

Tepper B. J. (2015 March 24). Real Sports with Bryant Gumbel: Depression in College Athletes. [Video]. https://www.youtube. $\mathrm{com} /$ watch? $\mathrm{v}=\mathrm{k} 3$ LsyzN18hs

Tyng, C. M., Amin, H. U., Saad, M. N. M., \& Malik, A. S. (2017). The influences of emotion on learning and memory. Frontiers in Psychology. https://doi.org/10.3389/fpsyg.2017.01454

Valant, J. (2018 August 29). The dangers of tribalism and callousness in college sports. Brookings. https://www.brookings.edu/blog/ brown-center-chalkboard/2018/08/29/the-dangers-of-tribalismand-callousness-in-college-sports/

Vainisi, J. (2016 April 16). University of Illinois finalizes \$250,000 settlement with Tim Beckman. Illinois Fighting Illini Football. https://www.thechampaignroom.com/2016/4/12/11414200/timbeckman-settlement-illinois-football-news

Waddock, S. (2016). Developing humanistic leadership education. Humanistic Management Journal, 1, 57-73. https://doi.org/10. 1007/s41463-016-0003-5

Walters, S., Spencer, K., Farnham, A., Williams, V., \& Lucas, P. (2018). Humanistic sports coaching and the Marist organization: A multi-case study in the Philippines. Journal of Sport for Development, 6(11), 1-11.

Whitehead, P. M., \& Senecal, G. (2020). Balance and mental health in NCAA Division I student-athletes: An existential humanistic view. The Humanistic Psychologist, 48(2), 150-163. https://doi. org/10.1037/hum0000138

Williams, C. (2019 October 8). College athletes beginning to rebel against abusive coaches. Global Sport Matters. https://docs. google.com/document/d/1GD53cEoetImp_rJvt55_hrU-WqWYv 1DJekGkZ6TlAfQ/edit

Woelfel, J., \& Haller, A. O. (1971). Significant others, the self-reflexive act and the attitude formation process. American Sociological Review, 36, 74-87.

Wolf, A. (2015 September 28). Is the era of abusive college coaches finally coming to an end? Sports Illustrated. https://www.si.com/ college/2015/09/29/end-abusive-coaches-college-football-baske tball

Yang, J., Peek-Asa, C., Corlette, J. D., Cheng, G., Foster, D. T., \& Albright, J. (2007). Prevalence of and risk factors associated with symptoms of depression in competitive collegiate student athletes. Clinical Journal of Sport Medicine, 17(6), 481-487.

Yukhymenko-Lescroat, M. A., Brown, M. E., \& Paskus, T. S. (2015). The relationship between ethical and abusive coaching behaviors and student-athlete well-being. Sport, Exercise, and Performance Psychology, 4(1), 36-49.

Publisher's Note Springer Nature remains neutral with regard to jurisdictional claims in published maps and institutional affiliations. 